\title{
Validation of sources of pertussis immunisation data
}

\author{
W. O. WILLIAMS \\ From the Royal College of General Practitioners' Research Unit, University College of Swansea
}

RICHARD DAJDA

From the Medical Sociology Research Centre, University College of Swansea

SUMMARY In this paper we describe the validation of three sources of immunisation data in a study of whooping cough in West Glamorgan. The least reliable source was that of the general practitioners and the best was that of the parents, but the area health authority source should be used in future studies provided that sufficient time is allowed for the relevant information to reach the computer.

The pertussis vaccine received a great deal of adverse publicity in 1974, resulting in a dramatic drop in the vaccination acceptance rate throughout the country. The worst affected area was West Glamorgan, where the rate had dropped from $36 \%$ in children born in 1972 to $9.5 \%$ in those born in 1974 ; these rates were very much smaller than the corresponding figures for England and Wales (76.5\% and $38.0 \%$ respectively). It was feared that this would lead to a considerable increase in whooping cough in the next peak, expected in 1977-78. The epidemic arrived at the beginning of the autumn of 1977 and developed into the biggest outbreak experienced for 20 years.

A detailed study of the epidemic in West Glamorgan was started at the beginning of November 1977, and ended in the middle of March 1979. All notified cases of whooping cough, and contacts, were examined to verify the diagnoses. In order to examine the protective effect of the vaccine, it was important to obtain information as accurate as possible on the vaccination history of the children living in the infected households. Before an analysis could be made to evaluate the effectiveness of the vaccine, all the possible sources of immunisation data had to be carefully examined for their accuracy and completeness.

Three sources of data were available: the area health authority (AHA), the GPs, and the parents, together with their children's immunisation record cards.

\section{Method}

These three sources of data were compared, to see how they tallied with each other, for 352 cases finally diagnosed as true whooping cough from the first 400 households with suspected cases notified to the West Glamorgan study. A separate study was carried out to test the reliability of the parents' memories and the children's immunisation record cards.

\section{(a) Comparison of data}

Vaccination records from the parents, together with their children's record cards and data from the AHA, had been recorded routinely on the study questionnaires. Immunisation records from the West Glamorgan AHA were extracted from the children's health files, except for records made after 1974, which were taken from data stored on computer. Vaccination information from GPs was requested on a special questionnaire form. At the end of the study it was thus possible to compare the three sources of immunisation data and to see, in particular, how well they tallied.

\section{(b) Testing the validity of parent source}

A separate study was carried out on a one in five sample of children vaccinated in a practice where a vaccination ledger had been accurately kept for over 10 years. The sample included children born both before and after 1974. The records were kept in alphabetical order according to the surname of the child. Each page was divided into columns to include the date of birth and the date of each dose of diphtheria, pertussis and tetanus (DPT) or of diphtheria and tetanus (DT). Data on every other type of immunisation given were also recorded, but were not used for this particular inquiry.

Research nurses from the West Glamorgan study visited the households of the children in the sample to 
interview the parents about the relevant vaccination history of their children. After the interview parents were asked if the nurse could see the child's immunisation record card, if they still had it. The secretarial staff of the Royal College of General Practitioners' research unit then obtained the children's immunisation records from the AHA, either from their health files or from a microfilm of computerised records.

The immunisation records from the practice, the AHA, and the parents were then compared.

\section{Results}

(a) Comparison of immunisation records of the 352 children diagnosed as suffering from true whooping cough

The parents, with the help of the vaccination cards when available, said that their children had been fully immunised with DPT in 110 cases. Many of these children had been vaccinated before the critical year of 1974 . Just over half $(51 \cdot 8 \%)$ of these cases were reported as having been fully vaccinated in the AHA records, and only $29.1 \%$ in the doctors' records. The reason for these low figures was absence of data rather than errors. However, only eight out of 37 practices said they were unable to give any information at all.

The AHA is informed of vaccinations carried out by GPs when claim forms are presented for payment. The West Glamorgan AHA, since the records have been computerised, sends copies to the doctor of records of immunisations carried out on his patients at the local authority clinics.

According to the AHA records, 70 children had been fully vaccinated. Of these $57(81.4 \%)$ were said by the parents to have been fully vaccinated. Only 18 (25.7\%) had been fully vaccinated according to the doctors' records. This means that there are many children vaccinated by the local authority for whom GPs have no records. Some GPs may also have no records for children whom they themselves have vaccinated.

Forty-seven children were said by the GPs to have been fully vaccinated with DPT. Thirty-two $(68 \cdot 1 \%)$ of these tallied with the parents' records and 18 $(38 \cdot 3 \%)$ with those of the AHA.

(b) The immunisation records of one practice compared with parents' memories and AHA records The total number of immunised children born between 1968 and 19.78 in the one in five sample was 150. There was a degree of non-response, due to patients moving from the district, changing doctors, or moving house without informing the practice. It was decided not to send letters to the parents before the nurse visited but to call unannounced so as to give less opportunity for refusals. Up to three visits were made at different times of day and on three different days before a particular household was left out of the study.

The nurses were able to obtain an interview in 107 houses; there were no refusals and the parents were very co-operative. The vaccination information was almost invariably given by the mother. The father, if present, often knew if the pertussis component of the vaccination had been declined. The record cards were still in the possession of the parents in $46.7 \%$ of the cases.

The parents' information on DPT or DT agreed exactly with the practice immunisation records in 70 $(65.4 \%)$ cases. Of the remaining $37(34.6 \%), 14$ $(13 \cdot 1 \%)$ were unable to say which vaccine and what doses of vaccine their children were given, and 23 $(21.5 \%)$ differed; in one of them, the mother had altered the DPT to DT because she said this was what her child had been given. This suggests that there had been a clerical error on the part of the practice. Thirty-four mothers said that they had objected to DPT because of adverse publicity on television. Nine had been advised by the doctor not to have pertussif vaccination, two because of a history of convulsions? one because the father was an epileptic, two because of asthma (although this is not now contraindication), one child was too old to be vaccinated against pertussis, and no reason could bs. given in the other three cases. The ledger records ot the child whose father was an epileptic said that the child had received DPT, yet the mother said that the doctor advised against it and the vaccination record card said DT only. This also suggests a clerical error on the part of the practice.

Dealing solely with DPT vaccination, the tally between the parents and the practice records was $73 \cdot 8 \%$. The tally between the parents and the AHA records was $75.7 \%$, and between the practice records and the AHA it was $79 \cdot 4 \%$.

\section{Discussion}

There is no doubt that a large number of parents had been influenced by adverse publicity about pertussis vaccine, especially when several severely brain-damaged children were shown on television and their lesions were blamed on the vaccine. This sort of spectacle would be more ingrained in the minds of parents than the descriptions of whooping cough given to them by friends and relatives. The parents had probably discussed it together, and would remember the decision they had come to on this very important matter knowing that the onus of responsibility was finally theirs and not the doctor's. 
It is interesting that in the results of the study of the first 400 households, the parent source tallies better with the doctors and the AHA separately than these latter sources tally together. The reason for this is that both the AHA and the GP sources have missing data on immunisation. The AHA is not notified of all vaccinations as soon as each is carried out because, for convenience and economy, returns are often sent in batches and at varying intervals. The GPs, on the other hand, were not being informed of vaccinations performed on their patients at local authority clinics before computerisation in 1974. Since then, computer printouts of these vaccinations have been sent regularly to each GP, but not every GP retains these records. The parents, on the other hand, have the advantage of knowing whether the child was vaccinated or not, and whether he or she was vaccinated by the GP or at the local authority clinic.

These studies have shown that in West Glamorgan the least helpful of these three sources was that of the GPs. The AHA would probably show underreporting of full DPT vaccination, at the time of extracting the data. In the parents' memories and vaccination cards study, there was a remarkable consistency between all sources of information and this gives support to the reliability of the parental source of data in the study. The true figure will be somewhere between the AHA and the parental source. It must be remembered that there were exceptional circumstances which made parents more aware of their responsibility in deciding whether or not to allow their children to be vaccinated against pertussis. However, in any future study to test the efficiency of the vaccine, it would be more convenient to use the AHA source, because the trend is towards more computerisation. This would particularly apply to continuous large-scale national studies monitoring trends of vaccination as well as its efficiency. The collection of information from parents using a large number of interviewers would increase observer error. If, also, the fear of immunisation against pertussis subsides, as it may well do, future parents may not be stimulated to remember details about their children's pertussis vaccination as vividly as parents of today.

We thank the nurses who took part in the study and the AHA staff who helped our two secretaries, Mrs. Anne Griffiths and Mrs. Phyllis Saunders, in extracting the immunisation data. The director of the unit is particularly grateful to the Department of Health and Social Security for the generous grant which made the study possible.

Reprints from Dr. W. O. Williams, Director, Royal College of General Practitioners Research Unit, Health Centre, Caebricks Road, Cwmbwria, Swansea. 